\title{
Introduction: The Evolutionary Way of Thinking in Economics $^{1}$
}

\author{
Ulrich Witt
}

Can we gain new insights about the human economy, its long term development, and its future by putting on the looking glasses of the theory of evolution? More than a century ago, when the Darwinian theory of natural selection began to thrive, Thorsten Veblen (1898) suggested to do just this. In the study of the life sciences in general and the study of human behavior in particular, the Darwinian theory indeed provides a fruitful and by now generally accepted, overarching frame of reference for research (see Brown and Richerson 2014). Not so in economics. Canonical economic theory is committed instead to the rational actor model and the theory of general equilibrium (see, for example, Mas-Colell et al. 1995). Both notions are rooted in classical, Newtonian mechanics (Mirowski 1989) which pre-dated the Darwinian revolution in the sciences. Not surprisingly, in the canonical economic perspective, the economy is usually seen as a sphere of reality for which the theory of evolution has little, if any, significance. Can such a perspective do justice to the observable unfolding of the economy, its growth and incessant transformations?

As a matter of fact, ever new products, technologies, organizations, institutions are thought up and tried out. They fuel an endless competitive struggle in which earlier vintages are outcompeted and the extant natural and social environment is transformed. New firms, industries, and markets emerge and grow while others stagnate or decline. In a relentless collective adaptation, institutions are designed and redesigned under economic and political pressures and made new. All this looks like a process of evolutionary change, albeit one that has a genuine new quality: it is cultural evolution. Under the influence of human creativity and deliberation it transforms the economy at a much higher pace than natural selection could do. Indeed, in cultural evolution, reproductive success under natural selection is only a long term shaping force or - in the language of multi-level selection theory - selection criterion (see Wilson 2015). In the short run, other, human-made forces shape the unfolding of the economy.

Several questions thus arise when an attempt is made to use the looking glasses of an evolutionary theory for gaining new insights on the economy. What are the principles governing economic change? What relevance does the Darwinian theory have for these principles? How can these principles help to improve economic theory? The chapters in the present volume seek to provide answers to these and other questions, which an evolutionary approach to economics faces. To pave the ground for the discussion, Part I of the book (Chapters 1 to 4 ) addresses three challenges confronting the application of evolutionary thinking in the economic context. First we need to come to grips with the fact that, in the literature, a variety of sometimes incommensurable interpretations of an evolutionary approach to economics exist. A second, albeit related, challenge is to identify what particular conditions characterize economic evolution. Do these conditions imply that the overarching 
evolutionary theory in the sciences is irrelevant for evolutionary theorizing in economics? The third challenge is to establish where and how evolutionary theorizing deviates from canonical (textbook) economics. Sections 1, 2, and 3 of this introductory chapter take up each of these three challenges in turn.

Sections 4 and 5 offer a preview of Part II of the book (Chapters 5 to 8). Center stage in this part is the role of novelty as a cause of evolutionary change. Section 4 outlines the epistemological and methodological problems, which the emergence of novelty implies for evolutionary theorizing. In the economic context, novelty comes in the form of discoveries, inventions, and innovations. Is their emergence to be treated as an exogenous shock or is it endogenous to the process of economic change? Accordingly the question is whether explaining the emergence is part of the task of economic theory. If so, what do we know about discoveries, inventions, and innovations and about how they come about?

Section 5 extends the perspective beyond the domain of economics. As argued later in the book, if novelty is a universal driver of evolution, its emergence and diffusion are abstract concepts - in fact, in a wider sense, Schumpeterian principles - by which the unfolding processes can be logically structured. However, especially the emergence of novelty plays a pivotal role also in the theory of self-organization. The point to be discussed then is how the emergence and diffusion of novelty relate to the principles of variation, selection, and replication which are often suggested for characterizing evolution in abstract terms. Put differently, given their shared interest in the emergence of novelty, it can be asked how selforganization and evolution - and the corresponding two paradigmatic interpretative frames in the sciences - relate to each other.

The subsequent Section 6 in this Introduction offers an outlook on Part III of the book (Chapters 9 to 14). This part sets out to show in an exemplary fashion what new insights an evolutionary way of thinking in economics can contribute. The cases to be discussed are taken from diverse research fields. Consumer behavior and the historical growth of consumption expenditures are discussed, as are the institutional conditions of cooperation and exchange. Further topics are the evolution of production technology, macroeconomic dynamics, and, last but not least, the theory of economic policymaking. Some conclusions are finally offered in Section 7 .

\section{Evolutionary economics - coping with the patchwork of concepts and theories}

Evolutionary thought has been gaining more attention in economics in recent years (Silva and Teixeira 2009; Hodgson et al. 2014). However, the interpretation of the attribute 'evolutionary' and, correspondingly, the concepts and models that are used vary substantially. While canonical economics presents itself as a coherent paradigmatic theory of optimization and general equilibrium, the contributions to evolutionary thinking in economics take the form of a patchwork of different ideas diversely pursued by different authors. Many of them agree, though, in their rejection of exactly the notions of optimization and general equilibrium as unsuitable for evolutionary theorizing. ${ }^{2}$ Agreeing on what needs to be rejected is, of course, no effective substitute for developing a coherent alternative. In this respect not much has changed since Veblen's (1898) initial plea for 'evolutionary economics' which he supposed to be the alternative to the neoclassical economic theory of his time.

Today 'evolutionary economics' is frequently associated with the Neo-Schumpeterian interpretation which is outlined in Chapter 1 of this volume. The Neo-Schumpeterians belong 
to those authors who oppose the rational choice framework and its focus on equilibrium states. Starting with Nelson and Winter (1982), they use a loose analogy to natural selection theory to instead describe the economy as being subject to an incessant transformation process. This process is argued not to be under rational control in any strict sense (see Nelson and Winter 2002; Metcalfe 2008; Winter 2014). The analogy to natural selection theory is based on a synthesis of two separate strands of thought. The first gives the school its name: it is Schumpeter's (1942) theory of innovative capitalism. Its thematic focus is on innovation competition, technical progress, and the growth of firms and industries.

The second strand of thought is the behavioral theory of the firm. This theory goes back to March and Simon (1958) and Cyert and March (1963) and draws on their concept of bounded rationality. According to that theory, firms heavily rely on the use of rules-of-thumb and organizational routines in their daily operations rather than systematic, discretionary rational decision-making. Nelson and Winter start from the assumption that the routines which the firms use are organizational inertia. If so, the profits of the firms can be argued to depend on how well-adapted the routines are to the competitive conditions under which the firms operate. Moreover, if profit differences between firms translate into corresponding differences in the firms' growth rates, the better adapted routines can be expected to become more prevalent within the industry. This means that firms using the right routines also grow in market share. In contrast, firms using less well-adapted routines lose in market share and eventually exit the market - and with them their routines. What matters for explaining economic change is thus the population level rather than the individual level.

The connection to Schumpeter's theory of innovative capitalism is made by interpreting the innovative economic process as a process of variation of firm routines. This is in noteworthy contrast to Schumpeter's (2002[1912]) explicit rejection of any biological analogies. Nelson and Winter and their Neo-Schumpeterian followers conceptualize the innovative transformation process in terms of an analogy to the theory of natural selection. They submit that innovations change the composition of routines in the industry's overall 'routine pool' much like mutations in the gene code of an individual organism change the distribution in the gene pool of a species. Over time, the forces of market competition then discriminate against firms with less well adapted routines. These routines tend to be driven out of the 'routine pool' like natural selection winnows out less fit genes. ${ }^{3}$ Changes in the composition of an industry's 'routine pool' are thus seen as adaptions not taking place at the firm level but at the industry level.

The loose analogy to natural selection models and algorithms and the corresponding 'population thinking' are the distinctive features of Neo-Schumpeterian approach (Metcalfe 2008). Whether, and, if so, how economic evolution relates to evolution on this planet more generally and cultural evolution in particular is not considered. The economic sphere of reality is treated as if it were a sphere of its own, distinct from the one for which the Darwinian theory of natural selection is directly relevant. Accordingly, no attempt is made to clarify what relevance the overarching interpretative frame of evolutionary research in the sciences might have for economics. Therefore, meaning which the attribute 'evolutionary' economics has for the Neo-Schumpeterians differs from, for example, that in evolutionary psychology and evolutionary anthropology.

As is argued in Chapters 2 and 3 of this volume, it can of course be asked why the Darwinian theory of evolution - properly extended in order to reflect the significant influence of culture - should not be considered relevant for the economic domain. Humans as economic agents are 
an outcome of evolution, after all. Why then not adopt the 'naturalistic' perspective on economic activities which the theory of evolution suggests? ${ }^{4}$

While not on the Neo-Schumpeterian agenda, this question was center stage in Veblen's (1898) version of 'evolutionary economics'. Veblen had been as critical of the rational choice assumption underlying the neoclassical theory of his time as Neo-Schumpeterians are of its present-day variants. But he drew different conclusions from his critique. The NeoSchumpeterians seek to solve the problem at a rather formal level. Making metaphorical use of, or constructing analogies to, the Darwinian theory, they substitute population-based selection algorithms for the discarded individual optimization algorithm. In contrast, Veblen thought of directly bringing to bear the substance of the Darwinian theory to develop a new way of thinking about the human economy. More specifically, Veblen $(1899,1914)$ traced the determinants of economic behavior back to instinct (genetic influences) and habit (the influence of cultural learning) and explored their role in the evolution of economic institutions. ${ }^{5}$

Once a naturalistic approach has been adopted, long term economic evolution can be re-cast as a history of the creative struggle of a unique species trying to expand its natural niche. The roots of such behavior can accordingly be identified in innate survival strategies that emerged under natural selection pressure when the ancestors of modern humans had to adapt to the ancestral environment. Seeing evolutionary economic change in such a long term perspective, further contributions to evolutionary thinking in economics come to mind. Among them, for example, are Hayek's (1988) theory of societal evolution by group selection (see Chapter 11 in this volume), North's (1997) particular brand of evolutionary institutionalism, and Georgescu-Roegen's (1971) work on the ecological constraints of economic evolution (see Gowdy 1994 for a discussion).

Chapter 4 in the present volume is devoted to drawing up a road map for an encompassing conception of evolutionary economics in which all these contributions have a place. For navigating purposes two criteria are introduced. The first concerns, what is called in the philosophy of science, the heuristic that an author uses. This refers to the interpretative frame that an author has in mind when she reflects on 'evolution'. This frame shapes the often tacit way in which she derives her 'evolutionary' hypotheses. As far as the heuristic is concerned, it turns out that one group of authors makes use of an abstract reduction of the Darwinian theory to three general principles: variation, selection, and replication. These principles provide a heuristic scheme originally suggested by Campbell (1965) for structuring evolutionary processes of whatever kind.

There is room for interpretation of this scheme, of course. Neo-Schumpeterians apply the three principles as inspiration for constructing their analogies between natural and economic selection (see Nelson 2006). For the proponents of Generalized Darwinism the three principles represent the analytical core of any evolutionary theory whatsoever (Hodgson and Knudsen 2010). In contrast to the group of adherents of Campbell's scheme, other authors like Schumpeter (2002[1912]) deny the Darwinian theory any relevance for understanding economic development. Schumpeter instead draws upon a heuristic frame originally developed in the 19th-century diffusionism (see Section 4 below). This frame focuses on the interplay of two other principles, namely the emergence and diffusion of novelty, in the evolution of human societies.

The second aspect dealt with in Chapter 4 relates to the ontological assumptions often only implicitly made by the various authors. These assumptions determine how reality is represented 
in a theory either by way of a monistic or a dualistic ontology. Roughly speaking, a dualistic ontology separates the sphere of nature from the sphere of cultural phenomena. The latter is given a distinct status: it is considered uniquely dependent on the exercise of the human mind. In contrast, a monistic ontology rejects the assumption of two separate spheres of reality. Schumpeter and the Neo-Schumpeterians make no statement of their ontological position. But by explicitly denying the Darwinian theory any relevance for the economic sphere (as Schumpeter does) or completely ignoring it (as the Neo-Schumpeterians do) they act as if they were ontological dualists. In contrast, authors like Veblen, Georgescu-Roegen, and, in his late works, Hayek take an explicit monistic position. For them, evolution in nature and the corresponding theory are relevant for understanding the evolution of the economy. Since ontology and heuristics are two independent features of evolutionary theories of economic change, the different combinations of these features are used in Chapter 4 for developing a typology of these theories. ${ }^{6}$

\section{Explaining economic evolution - how relevant is the Darwinian theory?}

As discussed in the preceding section, whether and, if so, how evolution in nature and evolution in the economy relate to each other is a matter of controversy. So, too, is the question of whether or not the Darwinian theory applies to explaining evolution in the economy as the overarching scientific framework. If evolution in nature and evolution in the economy are two entirely different pairs of shoes, the Darwinian theory can at best be relevant for the economic domain as an inspiration for constructing analogies. (This is the Neo-Schumpeterian position.) However, analogies of this kind are not without problems. This has been pinpointed by Winter (1964) with his - rhetorical - question regarding the economic analogue: "what are the genes?'7 Of course, there is neither anything in the economy that is comparable to the genes of natural organisms. Nor do products, technologies, industries, or institutions 'reproduce' in the sense understood by biology. Evolution operates via very different transformation mechanisms in the biological and the economic domain. The question therefore arises how far one can expect to get in explaining economic evolution by constructing analogies to the theory of natural selection.

If, alternatively, evolution in nature and in the economy is understood as representing interconnected processes, a different perspective emerges. Its focus is not on seeking analogies but on recognizing the continuity of the evolutionary adaptation process on this planet. The process started with the evolution of living nature and continues with the co-evolution of nature and human culture. Even though cultural evolution seems to unfold and shape the human economy according to its own rules and adaptation criteria, this process is embedded in, and continues to be constrained by, the evolution of nature. Such a 'continuity hypothesis', discussed in more detail in Chapter 3, obviously implies a monistic ontology.

The reason why cultural or, for that matter, economic evolution seems to follow its own rules is the pervasive role played in these forms of evolution by human creativity, learning, deliberation, symbolic communication, and knowledge accumulation. ${ }^{8}$ In the span of just one generation, multitudes of new products, technologies, industries, and institutions can now be purposefully created. Both creativity and knowledge that is being accumulated and broadly accessible are the basis of the human capacity to adapt to changing physical and social constraints in ever shorter periods of time. As a consequence, cultural/economic evolution has 
a much faster pace than evolution guided by natural selection. It is also characterized by a much higher rate of variation.

Differences between the two forms of evolution also concern the criteria that govern their adaptation processes. In evolutionary biology, the adaption criterion is the value of the heritable characteristics of an organism or a population for enhancing survival and having offspring, in short called their 'adaptive value'. It is measurable in terms of reproductive fitness of the organism or population carrying those characteristics. In theories of cultural evolution, including evolutionary economics, the concept of adaption and, hence, the corresponding criterion is much less clear. What is being improved here in the process of evolution?

Consider human societies living in an environment that implies a relatively high selection pressure on their members. Under such conditions, the adaptation criterion also governing the cultural evolution of these societies is likely to be reproductive fitness, that is, whether and how culturally acquired characteristics of human behavior enhance survival and having offspring. However, owing to the accomplishments of their cultural and economic evolution, many societies have gained control over their environment to such an extent that selection pressure on their members has slackened. Once this happens, reproductive fitness can be expected to lose its predominant role as adaptation criterion. In its stead, room seems to open up for a multitude of domain-specific adaptation criteria of which many may themselves be culturally contingent.

What can be said more specifically about the criterion governing the adaptation processes in economic evolution? Is it possible at all that there is one unique criterion, given that these adaptation processes represent the multitude of individually pursued attempts to accomplish one's goals - whatever these goals are? An answer to the question confronts the same challenge that economic theory faces with the task of substantiating the notion of welfare as a single criterion for economic progress. To derive more specific information we can take recourse to the continuity hypothesis and explore some aspects of human behavior that evolved in human phylogeny and now shape and constrain the paths that cultural and economic evolution can take.

The point of departure thus is the hypothesis that the human genetic endowment includes some motivational dispositions, that is, inclinations to act (drives, needs, emotions, see Chapter 9), that have emerged in ancestral times under selection pressure. These innate motivational dispositions are likely to have had adaptive value, in those times, in the sense of reproductive fitness. ${ }^{9}$ The motivational dispositions are still present, and widely shared (with the usual genetic variance), within the human population today. They can be expected to influence the goals that are pursued in the individual adaptation strategies in economic evolution even where reproductive fitness itself is no longer of overriding importance.

From an economic point of view, these innate motivations to act seem to have a significant consequence in common. More or less, the actions they induce come down to a striving for command over resources. This striving was clearly instrumental for enhancing survival and reproduction chances of the human species in times of severe resource shortage. As a consequence of cultural/economic evolution, living conditions in the highly developed modern economies with their relative resource abundance are now much different. Yet, the motivational dispositions and striving for raising income or wealth, which they imply, are still present and seem to establish an independent adaptation criterion for economic evolution. Where behavior 
generating greater resource command once meant being able to better adapt to the environment and have more offspring, behavior generating greater resource command now seems to have become a goal in its own right..$^{10}$

However, under the present condition, motivational dispositions that were once functional may now not only have lost their functional status. They may become dysfunctional. The result then is what biologists call 'evolutionary mismatch'. Indications of such mismatch can indeed be found in the economic domain in recent times precisely because the implied striving for greater command over resources can increasingly better be satisfied. Examples are innate consumption motivations and time discounting attitudes that tend to favor excessive resource consumption behavior wherever it becomes feasible. Such behavior was functionally advantageous for reproductive success under the ancestral scarcity conditions. With the present relative resource abundance it creates problems such as, for instance, obesity at the individual level and resource depletion and environmental degradation at the collective level (see Chapters 9 and 10).

Economic evolution can thus be claimed to unfold according to its own rules and adaptation criteria. This hypothesis is neither meant to imply that the unfolding is disconnected (in the sense of an ontological dualism) from the evolutionary process that continues to transform nature. Nor should the hypothesis be misinterpreted to postulate an end of co-evolutionary interactions between the human economy and nature. To the contrary, the evolving economy remains subject to the fundamental constraints of the co-evolving ecosystem in which it is embedded (see van den Bergh 2007 for an illuminating discussion). In the long run, the presence of these constraints means that human societies, if not the human kind in total, and the ways in which they run the economy are not exempted from the process of natural selection. This may only go unnoticed because, measured in human time scales, the pace of the latter process is extremely slow.

\section{Why deviate from the canonical economic paradigm?}

The notions of optimization and general economic equilibrium are core elements of the canonical economic paradigm (see, for example, Mas-Colell et al. 1995). As already mentioned, they are frequently criticized by the advocates of an evolutionary approach to economics. As far as the critique of the optimization hypothesis is concerned, it is neither new nor based on genuinely evolutionary arguments. In the form of the rational actor model, the optimization hypothesis is a heuristic that devises a template for explaining the actors' empirically observed behavior. The behavior is reconstructed - or rationalized - by means of 'situational logic' (Popper 1960, Chapter 31) as an instance of optimal decision-making. The underlying assumption is that choices are made rationally. This assumption, in turn, means: (1) the actors' choices are made deliberately; (2) the alternatives are represented sufficiently well by the subjective perceptions of the actors; and (3) their preferences are transitive and cover the complete set of alternatives.

The critics - among them many Neo-Schumpeterians - have argued long since that all these assumptions are a far cry from how, and on what basis, choices are actually made. More recent research in behavioral economics is now able to support the critique experimentally. Regarding (1) the deliberation assumption, it has been found that many choices are made on the basis of an automated decision system and, hence, without deliberation (Kahneman 2003; Loewenstein 2004). In the case of choices that are deliberately made, such deliberation can be biased by 
intervening emotions and wishful thinking. Decision-making then falls short of the standard of well-structured, logically-consistent thinking. ${ }^{11}$

Turning to (2) the subjective perceptions, the following finding is relevant. Due to constraints on time and cognitive resources, at any point in time, spontaneous individual information processing can cover only a limited number of alternatives potentially available. The individuals' perceptions therefore tend to represent more complex choice situations with a greater degree of imperfection. In response to this finding, Simon (1955) proposed the notion of bounded rationality more than half a century ago. More recently it has been noted that these constraints may be the reason for why intuitive thinking uses a set of 'fast and frugal' decision heuristics (Gigerenzer and Goldstein 1996). They obviously do not match the standard of full rationality.

Further evidence for distortions in subjective perceptions relative to the standard of full rationality is provided by the fact that the representation of the choice set is always contextdependent (see, for example, Glimcher 2015). Finally, regarding (3) the decision-makers' preferences, it is far from proven that the completeness and transitivity assumptions are satisfied. Especially when the set of potentially available alternatives is large and complex their complete and consistent representation in preference orders is doubtful. Yet, when the representation of the alternatives during the decision process is volatile, this can undermine the transitivity condition.

What consequences are to be drawn from this critique for the evolutionary approach to economics? As it seems, two alternative strategies can be chosen. One corresponds to the NeoSchumpeterian recipe of creating an evolutionary economic theory by means of analogies to natural selection theory. The strategy is to react to the critique by doing away not only with the particular rational actor heuristic, but also with methodological individualism in its entirety. Both are replaced by the methodology of selection models founded on population thinking (Nelson and Winter 1982; Metcalfe 2008). Accordingly, the focus shifts from explaining why individuals adapt their behavior to changing circumstances to instead explaining how selection mechanisms winnow out some variants of inert behavior ('routines') rather than others.

However, shifting focus from the individual level to that of the population means that, by the same token, evolutionary economic theorizing loses touch with the behavioral foundations of economics. This may appear as no great loss if, as in the Neo-Schumpeterian approach, the Darwinian theory is considered relevant for the economic domain only as a source of inspiration for analogy constructions. But if, in the spirit of the continuity hypothesis and its monistic ontology, the Darwinian theory represents the overarching scientific frame of reference, it is precisely in the behavioral foundations that insights derived from the Darwinian theory are most important. The neglect by evolutionary economic theorizing of the individual level would therefore come at a high cost. For this reason, the consequence to be drawn from the critique of the canonical optimization paradigm should be a strategy that maintains the individualistic perspective for evolutionary economic theorizing. Accordingly, the second strategy requires going beyond the rational actor heuristic and adopting a 'naturalistic' explanatory approach to economic behavior. More specifically, this means to elaborate an evolutionary behavioral economics as outlined by Burnham et al. (2015). ${ }^{12}$

The other core element of the canonical economic paradigm, the notion of general equilibrium, is tied to the following condition. The economy is said to be in a state of general equilibrium if, at a certain point in time, neither excess demand nor excess supply exists in any 
of its constituent markets. It is assumed that, in making their demand or supply decisions, the market participants have optimally accounted for their respective constraints. The general equilibrium condition then implies that all agents in the economy are not only able, but also have no reason to seek something better than, to realize their plans. However, as an empirical hypothesis such a claim is difficult to accept at least for modern economies. In these economies it can be observed that, at all times, at least some agents in the economy do seek to do better by pursuing innovations that would change their constraints. How can the general equilibrium hypothesis be defended against the implications of this observation? Is it at all possible to verify whether or not an economy is presently in a state of general equilibrium?

In view of these questions, a brief look at the history of the notion of general economic equilibrium is informative. In the works of classical writers like Adam Smith (1976[1776], Book I, Chapter 7), the notion of general equilibrium represented a logical construct. It described the fictitious end state of a process that would occur if all market participants had enough information and time to complete their coordination efforts. Owing to its fictitious status, this end state was not characterized with any great accuracy. It was recognized that, whether by market entry or exit, investment or disinvestment, variations in demand or supply, and so on, the actions of some market participants would always disrupt the coordination process before it reaches the end state.

The neoclassical revolution in economics at the end of the 19th century discarded this somewhat elusive classical conception of general equilibrium. Guided by the ideal of Newtonian physics, an attempt was made to replace it by what was considered a more exact interpretation. The latter was based on the calculus used in classical mechanics for physical systems such as the planetary system. By means of that calculus, a state of equilibrium can be determined as a state in which all free energy is dissipated. The calculus was analogously applied in economics to determine the general equilibrium in the markets as a state in which all excess demand and/or supply has vanished (Mirowski 1989). In contrast to the classical understanding of general economic equilibrium as a fictitious end point of the coordination process in the markets, the neoclassical interpretation holds that the general equilibrium state is reality. Modern canonical economic theory seems to subscribe to that claim (see, for example, Mas-Colell et al. 1995).

It is not clear, though, how to prove the claim. Except for highly-organized trading places it is very difficult, if not impossible, to empirically observe whether at a certain point in time all excess demand/supply has vanished and, hence, whether the markets are in a state of equilibrium or disequilibrium. In fact, it is usually simply assumed without further proof that the economy is in a state of general equilibrium - an assumption that is invoked not least for reasons of mathematical convenience. The unproven assumption is hard to accept for the adherents of an evolutionary approach. Instead, they consider Schumpeter's (1942) 'perennial gale of creative destruction' the adequate description of modern economies. Innovative as these economies are, they experience permanent structural change. This implies that, at any point in time, there are disequilibrium states at least in some of the markets. ${ }^{13}$

The theory of general economic equilibrium is often thought necessary for demonstrating the coordinating power of the price mechanism. However, as explained elsewhere (Witt 1985), general equilibrium theory represents the state of coordination in a highly idealized way as one with a perfect degree of coordination. The actual conditions under which the coordinating power of the price mechanism would have to be demonstrated are quite different. They are 
characterized by the presence of some excess supply or demand in the market system, for example, as a consequence of false expectations or the disruptive impact of innovative activity. As a consequence, the actual degree of coordination is not perfect.

Instead, the price mechanism is able to generate a viable degree of coordination in the sense that it suffices for most of the market participants to be able to get along in their economic affairs. Most firms will remain profitable. Most of existing labor supply will remain employed. Consumers will be able to obtain most of the goods and services which they demand. Very likely, though, the frustration of the plans of some agents by the market process may motivate those agents to pursue opportunities for innovative change on their part. Thus, the fact that some of the individual plans must remain unfulfilled if the degree of coordination is only 'viable' may disappoint some theoretical expectations. At the same time, however, it appears to be a constitutive element in keeping the market system innovative.

While in an evolutionary perspective the theory of a general economic equilibrium does not make sense, there is certainly room for a different notion of equilibrium in an evolutionary approach. Theories inquiring into evolutionary dynamics can, for example, be confronted with situations in which several processes of change interact in such a way that they produce a (temporary) stalemate between them. In that case, it is possible to conceptualize the ensuing situation using the equilibrium notion.

Equilibria of this kind obviously represent a rather special, transitory, state of affairs. In multi-layered, complex adaptive systems, such equilibria can typically be attained at one layer while the continuing developments at other layers prevent their adjustment dynamics from reaching equilibria simultaneously. As a result, the evolutionary way of thinking expects a stalemate situation at some layer to be disrupted sooner or later by the uneven pace of adjustments at other layers. For the complex adaptive system as a whole the disruption of equilibrium states is thus endogenously caused. The observation of an equilibrium at some layer of a complex adaptive evolutionary system - some part of the economy, say - should therefore alert the observer of processes at different layers which may already develop the potential for disrupting the equilibrium state.

\section{Schumpeter's 'diffusionism' as an incomplete approach to economic evolution}

In modern capitalism, products, production technologies, firms, markets, and other institutions are at all times in the process of being transformed more or less rapidly. The transformations ultimately result from the incessant pursuit and creation of novelty. The merit of having placed this insight on the agenda of economics belongs to Schumpeter and his theory of economic development (1934[1912]). He introduced the novel analytical concepts of innovation and imitation and elaborated the role that entrepreneurship plays for them. He argued that it is through the imaginative power and ability of pioneering entrepreneurs that major, sometimes even path-breaking, innovations come into existence.

The activities of these entrepreneurs involve establishing major new product lines, revolutionizing technologies and the structure of entire industries, mobilizing means to tap into and utilize new types of resources, and opening up the potential of new markets. When successful in their efforts, innovators can earn huge fortunes. For the transformation of the economy to be completed, it is necessary, though, that the success of the pioneering entrepreneurs encourages subsequent imitation processes. They require growing numbers of 'ordinary' business people whose imitate activities allow for the innovations to be diffused throughout the economy with more or less delay. 
The exalted view of entrepreneurial leadership promoted by Schumpeter was not unusual in the intellectual circles of early 20th-century Vienna to which he belonged (Streissler 1982). Also his interpretation of economic development as driven by the emergence and diffusion of novelty used a theoretical template then enjoying certain popularity. It figured prominently in the diffusionism school in social and cultural anthropology founded by the German geographer Friedrich Ratzel and in the 'Kulturkreis' doctrine of ethnologists Frobenius and Graebner.

The diffusionism school focused on how the development of homogenous cultural areas - a notion boosted, inter alia, by the discovery of language families - followed the patterns of regional emergence and diffusion of novelty. The school was understood as opposition to 19thcentury stage-evolutionism and its tenet that all human societies develop along the same lines, namely progressing from lower to ever higher stages. An influential branch of the school was associated with the research of Vienna social anthropologists Wilhelm Koppers and Wilhelm Schmidt. Although there is no record of a personal encounter between Schumpeter and these social scientists, his familiarity with their approach is evident. ${ }^{14}$ As Kobayashi (2014) has argued, it therefore seems plausible that Schumpeter's innovation-cum-imitation conceptual framework of economic development may have been inspired by the diffusionism school.

However, as is explained in Chapter 5 of the present volume, Schumpeter's grasp of the emergence and diffusion of novelty is in one respect incomplete. He argued that innovations spring 'from within' the economy, but failed to inquire into how their origin depends on inventive activities and their contingencies. Where Schumpeter (1934[1912]) did mention inventions this was just to distinguish them from innovations and to claim that, since inventions are always abundantly available, no further explanation of them is required. By making this claim, it became possible for Schumpeter to portray the economic transformation process exclusively as interplay of innovation and imitation..$^{15}$

However, successful innovations do not only elicit imitative activities. The innovator's success also puts increasing competitive pressure on established businesses. This creates incentives for these businesses to explore possibilities for their own inventions in order to escape the rising competitive pressures. Because of his neglect of inventive activities, Schumpeter did not recognize the feedback loop between innovations and inventions that keeps the economic transformation process going. Instead, he simply postulated that ever new 'swarms of innovations' will occur. In effect, Schumpeter thus treated newly invented products, techniques, and practices as 'falling from heaven'. Their occurrence is tantamount to an exogenous shock.

Such an interpretation of emerging novelty is, of course, more congenial to the conceptual frame of canonical economics than many Neo-Schumpeterians would be prepared to admit. When the occurrence of newly invented products, techniques, and practices is treated as an exogenous shock and their characteristics are assumed to be immediately known to the decision-makers, the way is paved for the use of optimization and equilibrium analysis. It is not surprising, therefore, that a variety of 'Schumpeterian' models were eventually developed in canonical economics exactly along these lines. They suggested optimal strategies for 'innovation' races, optimal investments in 'innovations', and the determination of market equilibria or even equilibrium growth paths arising from exogenous 'innovation' shocks (Reinganum 1985; Aghion and Howitt 1992). Aside from their Schumpeterian diction there is not much difference between these models and models of conventional investment calculus and comparative-statics game-theory. 
Returning to the connection between Schumpeter's theory of economic development and the diffusionism school in anthropology that opposed 19th-century stage-evolutionism, a more general question can be raised. That school had promoted a theory of cultural change that was independent of the contemporary Darwinian interpretations of cultural development. Schumpeter had a similar attitude and consequently denied that the principle of natural selection had any relevance for explaining economic development (Schumpeter 2002[1912]). It may therefore be asked how diffusionist principles for characterizing historical change at the most abstract level are comparable to selectionist principles. This topic is the subject matter of Chapter 6 in the present volume.

Since Campbell (1965) it is frequent practice to refer to variation, selection, and retention or replication as the abstract principles of the Darwinian theory. Whether or not the abstract representation makes sense for the Darwinian theory is controversial (see Levit et al. 2011). Nonetheless, the very same principles figure prominently in many attempts to formulate a generally applicable theory of evolutionary change. In Universal Darwinism (for example, Dawkins 1983, Hull 2001) and Generalized Darwinism (Hodgson and Knudsen 2010) these principles are claimed to properly account for all evolutionary processes, whether occurring in natural or cultural contexts. However, these principles have been attained through abstract reduction of the domain-specific elements of evolutionary biology. It is not evident that they would similarly result, if it would really be tried to distill abstract principles from observing evolutionary change in domains other than biology. How do the core concepts of diffusionism, that is, the principles of emergence and diffusion of novelty, by comparison fare. Are they able to characterize evolution (broadly understood as systematic historical change) in abstract terms in a manner that is not specific to any particular domain?

A reason for answering the question in the affirmative is that the principles of emergence and diffusion of novelty appear to be very general indeed. While not derived from the Darwinian theory, these principles are compatible with that theory, because variation, selection, and replication can be shown to be special cases. Variation of already existing elements is a particular, but not the only possible, way of generating novelty. Likewise, selective replication is the result of particular, but not the only possible, diffusion processes in which several variants compete for diffusion success. Further, the principles of emergence and diffusion of novelty are also compatible with constitutive properties of self-organization. Selforganization theory makes a distinction between two types of processes. These are (temporarily) self-amplifying processes which foster the emergence of new structures and self-stabilizing processes (Jantsch 1980) including the diffusion of new types or structures stabilizing their (co-)existence. Via the principles of emergence and diffusion of novelty, the two scientific paradigms of natural selection and self-organization can thus be connected in an advantageous way.

\section{Novelty and the epistemological bounds of economic theorizing}

Important as the process of emergence of novelty is for both evolution and self-organization, what happens in this process is poorly understood. As far as the economy is concerned, the emergence of novelty, coming in the form of new technologies, new products and services, or new organizations and institutions, is the mainspring of development and growth. Yet, economic theory usually treats their occurrence as exogenous shock which amounts to admitting that no explanation can be offered. It seems worthwhile therefore to more generally 
explore the reasons for the difficulties which the emergence of novelty poses. Such an exploration may also help clarify what, in spite of the difficulties, can positively be stated about the emergence. Chapter 7 in the present volume is devoted to this task.

The obvious epistemological limitation in dealing with novelty follows from the trivial fact that the meaning of novelty cannot, by its very nature, be anticipated. The specific content needs to be recognized or experienced which is possible only once novelty has occurred. Where novelty arises from recombining pre-existing elements, the epistemological problem can be determined more precisely by noting that two logically distinct operations are involved in the emergence of novelty. The first is a generative operation producing new (re-)combinations of pre-existing elements. The second is an interpretative operation identifying the meaning which the new combinations have in the context in which they occur.

The generative operation can be emulated mechanically or by a computer program and in simple cases even be described by a mathematical algorithm. This means that the generative operation does not pose any particular epistemological problem. Its results can often be characterized in generic form ex ante, for example, by means of a probability distribution. This is different in the case of the interpretative operation. It can neither be emulated by any means nor is it possible to characterize its outcome (that is, the meaning, if any, of the newly generated combinations) ex ante. ${ }^{16}$ The epistemological constraint is binding. In the case of novelty mentally created by recombining pre-existing content, the reason is the complexity of the associative act of attributing meaning to the new combination (the core of the interpretative operation). This associative act is achieved in the brain in a way in which the complexity is far greater than presently understood.

It may of course be asked whether the epistemological constraint on the interpretative operation is equally binding for all kinds of mentally created novelty. One newly created action may mean a radical break with everything that was previously known or expected, while another novel action may just mean a minor deviation from what preceded it. For example, the creation of computerized book keeping does not seem comparable in this respect with the creation of just a new book keeping rule. Are the epistemic limitations equally binding ex ante no matter how 'radical' the emerging novelty is, or at least appears, when looked upon expost?

In order to be able to distinguish between those instances of novelty that appear to be more radical than others, an ex ante measure for degrees of novelty is needed. Chapter 7 discusses such a measure and its prerequisites. The distinction between the generative and the interpretative operations is again a good starting point for the inquiry. Considering the generative operation in isolation, it is often possible to construct a probabilistic measure regarding its outcome. Because of the binding epistemological limitation this is not possible for the outcome of the interpretative operation. The simple reason is that the state space on which the probability measure would have to be defined cannot be pre-specified. It is for the interpretative operation therefore that a measure for degrees of novelty is relevant. Once established, a comparison of this measure with the probabilistic measure, that is, between degrees of likelihood and degrees of novelty, is straightforward. As will turn out, the epistemological difference between degrees of probability and degrees of novelty translates into a continuous measure of uncertainty for the former and a basically dyadic measure of uncertainty for the latter.

Two further problems arising from the 'bound of unknowledge' implied by the emergence of novelty are outlined in Chapter 8 of the present volume. The first revolves around the 
question of whether the principle of causation has to be given up whenever within the explanatory domain of a theory it is possible that novelty emerges. This is sometimes argued to be necessary (see Hodgson 1995; Koppl et al. 2015). In discussing this claim it is useful to distinguish between two different problems relating to causation. The first problem is associated with the explanation of why novelty occurs: is there a cause for why economic agents create novelty? The second problem is related to the content of novelty that is being created: is there a cause for why it has the particular meaning that is recognized ex post?

In the first case, it is not difficult to find out that there is a cause. It is the reason that motivates economic agents to search for, and arrive at, novel ideas, artefacts, or actions. In the second case, however, the associative act that is mentally carried out in the process of identifying meaning is so complex that a detailed attribution of specific causes is not possible. Yet this does not mean that there are no causes. The attempts presently under way to improve our understanding of the 'conceptual integration' that happens in the associative act are all designed to develop causal explanations (see Fauconnier and Turner 2002). The fact that a binding epistemological constraint exists is not sufficient to support the claim that, with respect to novelty, the principle of causation and the scientific ideal of causal explanations must be renounced.

The existence of epistemological constraints does present some difficulties, though, for devising theories about the development over time of systems in which novelty emerges. This is the second problem to be discussed in Chapter 8 . Where the occurrence of novelty cannot be ruled out ex ante, the epistemological constraint impedes the ability to positively predict future developments. The problem is relevant, in particular, for explaining and predicting economic time series by means of difference or differential equations as, for example, in theories of the business cycle or of economic growth. By these equations the future development over time is predetermined once the initial conditions are specified. In the sciences such equations can be used to explain the development over time if at least one of two provisions is satisfied. Either the emergence of novelty is not to be expected (such as in the movements of the planetary system) or it has no effect on the trajectories (such as in the case of natural laws that remain valid whatever novelty will emerge) ${ }^{17}$

Neither of the two stipulations is, however, satisfied in the economic domain. The possibility of novel products, techniques, policies, regulations, and so on occurring in the future cannot be excluded. Nor can the possibility be excluded that, as a consequence of their occurrence, changes in the previously observed regularities occur - in economics there are no natural laws, after all. As explained, the concept of probability is inadequate for characterizing the unknown effect of such changes. Therefore, the practice of adding a randomly distributed error term in economic models is no option to solve the problem of the unknown effects. Changes in the very structure of the economic models can be neither excluded nor anticipated. For that reason, it is highly misleading when the impression is created that the prevalent use of differential and difference equations in economic theory and time series analysis can effectively predict the development of an innovative economy except for some random 'noise' The truth is that the reliability of predictions of time series models for innovative economies is poor and that this should not be unexpected.

\section{Elements of an evolutionary economic theory}

Conceptual, methodological, and historical reflections about an evolutionary paradigm in economics are important. But ultimately the test of the paradigm will be what theories it 
inspires and what new insights on the economy these theories can provide. Part III of the present volume is therefore devoted to presenting selected elements of economic theory that are informed by evolutionary thinking. Chapter 9 starts with an important part of what has so far been widely neglected in evolutionary economics, namely a properly founded evolutionary theory of economic behavior.

On the one hand, there is ample evidence for the influence of genetic dispositions on economic behavior that change very slowly, if at all (first and foremost among them innate motivations such as instincts, drives, needs). On the other hand, history teaches that economic behavior is extremely malleable. The human genetic endowment must therefore comprise mechanisms that make the malleability, that is, rapidly adapting behavior, possible. One of these adaptive mechanisms is represented by reinforcement and conditioning learning shared by all humans and other animals as well. The other adaptive mechanism is that of cognitive and observational learning. Given the unique human capacity of memorizing and communicating, both mechanisms allow the accumulation of an ever more extended and differentiated cultural knowledge..$^{18}$

Chapter 9 sets out to demonstrate the relevance of the approach for the case of consumption behavior and its evolution. A key role has to be attributed in this context to the motivational aspects of individual behavior. While they figure prominently in psychology, ${ }^{19}$ in economics questions about individual motivation are subsumed within the terra incognito of individual preferences. Unlike time preferences, risk preferences, and other-regarding (altruistic) preferences, which have recently gained attention in behavioral economics, consumption preferences proper continue to be a neglected research topic. It is not surprising, therefore, that little progress has been made with the explanation of the enormous changes that have occurred and are going to continue on the demand side of modern economies, that is, in consumer behavior.

In order to make progress it is necessary to understand the motivations that are expressed in the consumers' preferences and the effects of the mentioned adaptive mechanisms on changes in these motivations. In a rough sketch one can refer first to the category of innate motivations such as the need for food, clothing, and shelter, which affect consumer preferences. They are likely to have been shaped in ancestral times because of their contribution to survival and reproductive success. Since humans have always been social animals involved in social competition for reproduction, the same holds for the motivation to seek social status and social recognition. Another important motivation for consumption behavior that seems to be hardwired into our genetic endowment is that for seeking 'arousal', that is, cognitive and emotional stimulation.

A feature of innate motivations that is significant in the context of consumption is their satiability. If a need such as that for food is completely satiated, the motivation to consume in this case to eat - vanishes (except when there are also other motivations for eating that are not yet satiated). The question then is how quickly satiation occurs in terms of pro rata consumption when the ability to spend increases as a consequence of rising levels of per capita income. Differences in the patterns of satiability are apparent in the shape of Engel curves based on aggregate household expenditure data on consumption categories serving the corresponding needs.

For example, where data on long term expenditures are available, it can be seen that the share of food expenditures relative to all household expenditures consistently decreases over 
time as well as across income percentiles. In contrast, the relative expenditure share of the consumption category of housing has steeply increased. The expenditure category can be associated with the status-seeking motivation (Frank 2010) that is not easily satiable when income rises. The reason is a tendency toward an unstable expenditure race. It is caused by the positional character of social status and how, as a result, relative positions remain unaffected by similar increases in the spending within a comparison group (Frank 2012). Also strongly increasing are the relative expenditures shares of entertainment and tourism. ${ }^{20} \mathrm{~A}$ major motivation for spending on these two categories can be conjectured to be seeking a certain level of 'arousal'. This motivation is not easily satiable either. However, in this case, the reason is a stupefaction effect (Scitovsky 1981) or hedonic adaptation process which arousal is subject to. In order to uphold a comparable level of arousal, consumption of new and stronger stimuli is continually required which tend to be more expensive.

Besides the innate motivations that drive individual consumption behavior there are culturally conditioned motivations as well. They emerge from the two adaptive mechanisms of conditioning learning, that is, learning of reinforcers (Leslie 1996, Chapter 2.14) and cognitive learning. Formed over a lifetime history of individual learning, this class of motivational forces explains a substantial part of the huge variety of, and idiosyncrasies in, individual consumption expenditures. If the ability to spend increases, the motivation to consume items that serve these culturally conditioned motivations does not seem to vanish. To the contrary, higher expenditures seem to induce a more intense learning. As a result consumers develop increasingly differentiated tastes and a corresponding willingness to pay for differentiated goods and services. Due to constraints on the opportunity and time for learning, the differentiation process cannot cover the entire range of possible, culturally conditioned motivations. It is rather a selective process during which consumers learn to specialize in what they favor and consume (Witt 2001).

Chapter 10 extends the inquiry into consumer behavior and its historical evolution to considerations of possible normative aspects. The focus of this chapter is on the consequences of a growing material consumption of the human species. It impacts on a natural environment that can ultimately offer this species only a finite niche to meet its needs for survival. Unfortunately, despite all its achievements, cultural evolution has not been able so far to generate practices that bring the social costs of the global growth of consumption under control. How should the omnipresent quest for further growth of income and consumption be assessed in this light?

In less developed economies, calls for economic growth and more consumption are motivated by the fact that many consumers are deprived even with respect to more easily satiable needs such as food and shelter. In their miserable situation, raising per capita income and consumption has high priority even if can only be accomplished at the cost of severe damages to the natural environment. In wealthier, more developed economies such deprivation is no longer present. Nonetheless, the striving for additional material growth does not vanish. The quest for more consumption is only motivated differently, namely by the less easily satiable needs and by culturally conditioned and cognitively constructed motives, standards, and norms of consumption (such as those of signaling status, see Witt 2010). However, expanding consumption means no less more material consumption that increases environmental stress and degradation and resource depletion.

In view of the detrimental environmental effects of further growth of material consumption, the question arises whether the motivations that drive the process and the significant differences 
between them in rich and poor economies, respectively, are ethically relevant. Is the quest for further consumption growth equally legitimate independently of whether it is articulated in rich or poor economies? More specifically, if global consumption growth needs to be constrained, what weight should be given to issues of fairness and justice regarding the question where to curtail the expansion first? These issues have a long history. ${ }^{21}$ They can now be discussed on the basis of a more detailed understanding of consumer behavior provided by an evolutionary behavioral theory of consumption.

The problem of the social costs of material consumption and the prior production processes can neither be solved by private negotiations (as considered by Coase 1960) nor to political bodies hampered in their decision-making by interest groups. What seems to be needed instead is a more enlightened attitude of the consumers regarding the ethical relevance of their consumption motivations particularly in the wealthier economies. Consumers need to be invited to reflect on the innate dispositions and learned motivations that guide their consumption behavior, especially in light of the fact that marketing and advertising efforts often try to prevent this from occurring (Scitovsky 1962).

Such reflections can presumably only be hoped to be triggered by a broad public discourse on the moral legitimacy of the various motivations underlying consumption which consumers can assess for themselves. Consumer sovereignty represents a significant ideal in a free society, but it should not be mistaken for prohibiting a discourse of this kind. Accepting responsibility for the consequences of one's own action is an equally significant ideal in a free society and a fundamental ethical postulate. It demands reflection of what motivations are driving one's action - in this case striving to expand consumption - and the decision of whether or not the motives are worth the consequences that ensue.

Chapter 11 turns from consumer behavior to an evolutionary perspective on behavior in situations of social and economic exchange. Social exchange behavior is a characteristic of all social animals, but particularly of humans. A key problem of human sociality is keeping defection and free-riding under control. It is likely that the problem has been solved already in the life of the small bands of the early humans by the evolution of partly inheritable, partly socially conditioned cooperative social exchange behavior and moral aggression against offenders (Boehm 2012). In the course of history, human sociality of course outgrew the conditions of small bands and their solution of the problem. Living in larger social formations and the corresponding changes in the division of labor required further adaptations not least to make economic exchange and trade possible. These are much more recent, cultural adaptations. Nonetheless, the genetic dispositions that had originally evolved in relation to social exchange behavior seem to have intuitively been extended to situations of economic exchange within and between much larger groups.

Such an 'exaptation' (Gould 1991) of inherited social attitudes explains why norms of reciprocity and fairness - originating from the realm of social exchange in small groups - can also have affective value for the broader economic exchange behavior. There is one proviso, however: the economic exchange partners need to be seen the same way as social exchange partners are seen, namely as being equals or peers and close to oneself. If that proviso is not met, particularly in anonymous interactions, norms of reciprocity and fairness are unlikely to be felt as binding in economic exchange behavior. In that case, economic exchange will only be possible, if other ways of preventing or sanctioning defective behavior in trade can be developed. They face the problem that an individual contribution to enforcing cooperation 
amounts to the provision of a public good. While the group as a whole would benefit from the existence of credible enforcement, individual group members may incur substantial costs from having to engage in enforcement activities and may therefore be tempted to free-ride. ${ }^{22}$

Chapter 11 examines a cultural adaption process that can be imagined to solve the problem without presuming that formal institutions capable of credibly sanctioning defection already exist. The framework chosen for the discussion is the theory of cultural evolution suggested by Hayek (1988). In this framework it is essential for group behavior - and, hence, the conditions for group selection - to be able to change as a result of within-group imitation and between-group migration (see also Richerson and Boyd 2005). Accordingly, the specific form which group behavior takes becomes dependent on observational learning as a way of determining one's behavior. The decision between free-riding or instead contributing to costly punishment activities hinges on what other group members are observed to do. The relative advantage of the one behavior over the other is determined by the relative frequencies with which the respective behavior has been adopted in the group. Owing to the corresponding balance between individual fitness and the group's fitness, it is possible that groups with a high frequency of punishing behavior can enforce the conditions required for economic exchange and can thus become more prevalent.

Keeping the threat of defective behavior under control is also necessary to protect investment in production capital and the deepening of the division of labor. However, besides a favorable institutional context, improvements in the capital stock and its production technology also depend on the development of productive knowledge, that is, knowledge necessary to exploit natural resources better and more widely. This is the topic of Chapter 12 in the present volume. From the evolutionary perspective, the interaction between the growth of productive knowledge and the expanding anthropogenic utilization of nature should be seen as the constitutive element of an economic theory of production.

In economic theory, production is traditionally interpreted as being constrained by the availability of capital, labor, and land. These factors of production have been conceived by the classical economists of the proto-industrialization period to represent the proper analytical concepts for one particular reason. These economists were interested in elaborating on (and often also castigating) the manner in which the social product was distributed. Since this time, few economists have found it necessary to reconsider and ultimately challenge the classical conception of the factors of production. One important exception in this regard is Nicholas Georgescu-Roegen (1971). In his view, the traditional approach does not adequately reflect the true constraints on human economic activity, namely those imposed by the laws of nature and the laws of thermodynamics in particular.

In a similar vein, Chapter 12 takes up the question of how the conceptual underpinnings of production theory can be improved by adopting a naturalistic perspective. More specifically, to induce such a perspective, a comparison between non-anthropogenic productive processes in the biosphere and human production processes is suggested. The results of the comparison are, first, a critical reappraisal of the conventional understanding of 'productive' factors and why capital, labor, and land have been chosen to represent them. These factors are appropriate for an analysis of how economic surplus is distributed once it has been generated. They are of less help for explaining how this surplus is generated in the first place. For this reason, the traditional attempt to simultaneously explain both the generation and distribution of economic surplus appears less convincing than usually assumed. 
Second, in exploring non-anthropogenic productive processes in the biosphere it becomes apparent that the analytical concept of productive factors can be used there as well, albeit for knowledge, energy, and matter as factors of production. If anthropogenic production processes are analyzed in terms of these factors, a different explanation for the generation of surplus results. Third, the role of the factors knowledge, energy, and matter seems to condition, but not to replace, the role of the traditional factors capital and labor when it comes to explaining the historical growth of human production. To clarify the relationships between the different sets of productive factors is therefore a major task for an evolutionary theory of production. An inherent advantage of such a theory is the integrative view of economic surplus generation and its environmental and resource effects.

Nothing has so far been said in relation to how the evolutionary way of thinking can be brought to bear on macroeconomic theory. In Neo-Schumpeterian evolutionary economics the question has no high priority as most of the work focuses on economic processes at the 'meso'level (Dopfer et al. 2004). When macroeconomic topics are addressed, this happens for the most part in data-driven international comparisons of technology-driven growth and catching up processes (see Fagerberg 2003 for a survey). One characteristic of canonical macroeconomics is its strong reliance on the concept of market equilibria when analyzing the aggregated markets for goods, and services, labor, and money. This concept is the equivalent to the already criticized notion of general equilibrium in microeconomics. From an evolutionary point of view, it is straightforward therefore to start with a discussion of the role of equilibrium concepts in macroeconomic contexts.

Opposition to the corset imposed by the equilibrium condition on macroeconomic processes has traditionally been voiced in the Keynesian and post-Keynesian literature. However, this literature has little in common with the evolutionary way of thinking (see Foster 2011). Chapter 13 therefore approaches the problem in a different, namely Hayekian (rather than Keynesian), spirit. Hayek had earned much of his academic reputation with his writings in the 1930s on capital theory, monetary theory, and business cycle theory (nowadays considered macroeconomic topics see, for example, Hayek 1941). In the 1950s he turned his back on these topics (McCormick 1992) and started to work instead on social philosophy and his theory of societal evolution (see Hayek 1979 and 1988). With the new orientation of his research he also abandoned the notion of general market equilibrium on which he had heavily relied in his earlier work on macroeconomics. The new, and much weaker, notion which he developed in his social philosophy was that of a spontaneous order of the markets. Can this notion also be applied to macroeconomic contexts and, if so, what would it imply? In a littleregarded paper Hayek (1981) presented an answer in terms of a flow metaphor.

In the markets countless individual decisions are made with respect to businesses that are set to materialize at some time in the future. These decisions reflect the information about future states of the economy available to the agents when their choices have to be made. Yet, the states of the economy frequently change in between the time of making decisions and the time at which the planned transactions are set to occur. It is likely therefore that the flow of goods and services supplied or demanded in any point in time does not match the market conditions that actually prevail. As a consequence, the originally planned businesses are often likely not to materialize as planned.

Nonetheless, the flow itself may be in equilibrium if the stream of goods and services entering and leaving the market is just balanced. This means that the notion of 'flow equilibrium' 
at the macro level is compatible with a situation of market disequilibrium in many or most markets at the micro level, provided the markets are cleared. The prices prevailing at a given point in time may clear the market, but do not perfectly coordinate the individual plans. There will instead be surprises, excess supply or demand, corresponding losses and misallocations. They negatively impact many agents involved, although not to the extent that would force more than a minority out of business. This is the case of a viable rather than perfect state of coordination as it was called in Section 3 above.

Accordingly, Chapter 13 elaborates on the notion of macroeconomic flow equilibrium as an alternative to the concept of general equilibrium and its macroeconomic equivalent. It is explained how a flow equilibrium can be used as a benchmark for assessing fluctuations in aggregate economic activity. These fluctuations are commonly associated with the business cycle. In canonical macroeconomics they are interpreted as a result of exogenous shocks that disrupt the existing equilibrium states of the markets. In contrast, the notion of flow equilibrium suggests that deviations from the flow equilibrium build up endogenously from earlier ("upstream') decision-making in the markets leading to excess demand or supply of a size that cannot instantaneously be cleared by the price mechanism. A macroeconomic model is presented in which some variables appear that are not usually considered in the macroeconomics context, but are helpful for capturing important aspects of the flow concept. The role which these new variables perform is highlighted by means of an empirical investigation utilizing data for the period from the time of the German unification until 1994.

Finally, Chapter 14 in the present volume turns to economic policymaking from an evolutionary point of view. If economic evolution is the process by which the economy selftransforms, then policymaking obviously represents an integral part of this process. A first consequence to be drawn from an evolutionary perspective therefore is that the activities of policymakers need to be made an endogenous factor in explaining economic change. This is far from being the standard approach. ${ }^{23}$ In many contributions in the literature, "policy implications' of the presented work are discussed in the following way. The author(s) ascribe some set of goals to a fictitious (and usually benevolent) policymaker and assume that the advice which the presented work can give on how to reach these goals is needed (see Tinbergen 1967 for the classical statement of such an instrumental approach to economic policymaking). Another variant of the works on economic policymaking is couched in normative or prescriptive terms. These contributions discuss the policy goals and their legitimacy in relation to a (hypothetical) set of normative criteria in the form of an applied ethics.

The evolutionary way of thinking is compatible with any of the approaches to economic policymaking. Its characteristic is, however, to extend the approaches so as to account for the pervasive role of learning and innovation - the constitutive features of cultural/economic evolution. Although this extension may appear trivial, its consequences are all too often underrated. In an explicative approach to policymaking, the upshot is that the policymaker's understanding of what a certain policy mix involves is subject to systematic changes which are contingent on the experiences to be made. Politicians no less run down a learning curve in this respect than technicians or managers do with respect to their tasks. For that reason, the process guiding how policymakers learn and the effect of different institutional conditions on their learning deserve attention. This is all the more true as the learning process can also involve changes in the interests which policymakers pursued. Constellations of interests and power can therefore not simply be taken as given as is typically done in public choice theory. 
For an instrumental approach to policymaking, acknowledging the significance of learning and cognitive deliberation means to recognize that also the addressees of policy measures are likely to learn. Specifically, those agents detrimentally affected by some particular measure have incentives to engage in an active search for remedies. As a consequence, they often respond to the policy measure in innovative ways. Policymakers may then be forced to over and again readjust their policy design in order to reach their goals. The assessment of the suitability and effectiveness of policy measures should therefore include reflections on what incentives a measure creates for innovative responses and what likely directions the search for remedies may take. Moreover, since innovative responses cannot be anticipated, the design of policy measures should already account for the fact that future readjustment will be required. One possible solution is to implement an adaptive or 'rolling' policymaking design from the beginning (Metcalfe 1994; van den Bergh and Kallis 2013).

Concerning the normative side of economic policymaking and its goals, the evolutionary way of thinking does not coincide with any one specific norm or set of norms. An attempt to drive any particular normative foundation from a positive theory of evolution would constitute a naturalistic fallacy. As a matter of fact, cultural evolution has produced a multiplicity of often incompatible norms and value judgments at different times and places. This is a result of learning taking place also with respect to normative judgments (so long as emotional barriers do not forestall such learning). Individual norm preferences and the value judgments that constitute them are malleable. They may change as a result of factual experience and/or under the influence of social conformity pressure and operant conditioning. While the influence of experience tends to undermine claims to the supremacy and absolute validity of particular norms (as found in many totalitarian ideologies), this is not necessarily true for the other influences. At the experiential level, the culturally contingent diversity of norms and value judgments may be interpreted to imply a certain norm-relativism. Awareness of this implication may prove helpful in protecting against totalitarian norm preferences.

\section{Conclusions}

Modern economies are in a permanent process of being transformed. How can these transformations be explained? What modifications are required to the existing concepts and methods in economics in order to be able to account for evolution in the economy? Some preliminary answers to these questions have been provided in this Introduction. In previewing and putting in perspective the chapters in the present volume, a wide range of topics has been covered. The aim was to give an idea of what is implied by the evolutionary way of thinking about the economy. Unsurprisingly, the complexity of economic evolution allows for many different, and sometimes perhaps incommensurable, interpretations of 'evolutionary economics'. Some of these interpretations have been discussed here, along with their specific reasons for why all of them deviate from the optimization-cum-equilibrium core of canonical economics.

The particular approach to evolutionary economics pursued in this volume can be called a naturalistic one, given that it is founded on the continuity hypothesis briefly explicated above. In such an approach there is room for co-evolutionary interpretations (Richerson and Boyd 2005) and multi-level selection theory (Wilson 2015). The particular focus is on the pervasive role of learning and innovation as the characteristic features of economic evolution. It is on account of these features that economic evolution is ultimately the consequence of the 
ceaseless human quest to not only adapt to, but overcome the constraints of the natural and social environment. A central element of the explanatory framework of evolutionary economics understood this way is therefore the emergence of novelty and its often ambiguous character. On epistemological grounds, the emergence of novelty implies bounds of unknowledge for any form of economic theorizing. However, it should have become apparent that, despite the epistemological limitations, the evolutionary way of thinking has to offer fruitful new research perspectives on classical economic topics such as consumption, exchange, production, macroeconomic dynamics, and economic policymaking.

\section{Notes}

1. Thanks go to Chad Baum for helpful comments on an earlier draft of this Introduction.

2. There is no general consensus on this point, however. Evolutionary thought often takes the form of algorithms and models that are borrowed from evolutionary biology. Reliance on such methods can also be interpreted as an enrichment of, rather than an alternative to, canonical economics. This holds in particular for evolutionary game theory, see, for instance, Weibull (1995), Samuelson (2002), as well as the critique of Hodgson and Huang (2012).

3. Assume that a firm's innovation allows reducing the unit production costs. Then the average unit cost in the industry is also falling and, so too, is the industry's price level under competitive conditions. Non-innovative firms with higher unit costs will sooner or later be driven out of the market. Formally, the competitive process can be modeled as a variant of the replicator dynamics (Metcalfe 2002).

4. In such a perspective, a core issue that needs to be clarified is the deeper reason for why the transformations of the economy are relentlessly driven forward. An answer to this question demands a deeper appreciation of the motivational aspects of human nature than has so far been attained in economics (see Witt 2011). For a more general discussion of a naturalistic economic philosophy see Herrmann-Pillath (2013).

5. For a survey of Veblen's approach and its further fate in the 20th century see Hodgson (2004).

6. For a critique of the suggested typology see Rice and Smart (2011). Their critique is misled in so far as they interpret the two features, heuristic and ontology, as necessary conditions for, rather than just characteristics of, evolutionary economic theories. However, they rightly argue that classifying authors with respect to whether or not their heuristic stance involves the principles of variation, selection, and replication - as done in Chapter 4 - can be problematic. There is much room for interpretation indeed when the authors' publications precede the formulation of these principles in Campbell (1965).

7. The question referred to the early controversy about natural selection analogies in economics between Alchian (1950), Penrose (1952), and Friedman (1953). Remarkably, at that time, Winter discussed the controversy with a quite critical attitude toward such analogies.

8. See Witt (2015) for a discussion. Although learning necessarily takes place at the level of the individual agents, it is nevertheless strongly shaped by the social interactions in which they take part. In groups of individuals who continually interact with each other, socially contingent learning can thus generate shared knowledge in the form of mental habits, values, and norms. When knowledge can be encoded in symbolic form, it becomes present outside the individual mind and can be accumulated and transmitted between individuals and between generations independent of face to face interactions.

9. They do not differ in this respect from other innate mental traits for which this argument has been made in evolutionary psychology, see Buss (2003).

10. In his theory of societal evolution, Hayek (1988) argues in a similar vein that it is economic fitness rather than reproductive fitness that matters for societies. Those of them with a culture and with instititions - customs, rules of conduct, and economic order - that are better adapted according to this criterion enjoy comparative prosperity. It is their prosperity that then allows these societies to expand and their culture and institutions to spread. Such societies may have higher population growth due to higher birth rates or due to immigration. Or they may impose their characteristics on populations in foreign territories which they are able to conquer or dominate; see Gray (1998) and Beck (2015) for a discussion.

11. See Loewenstein (2000). Logical calculus is, after all, nothing humans are naturally endowed with. It is a cultural achievement that required millennia of human reflection to be developed and contrasts with what, in the light of the logical ideal, are perceived to represent the shortcomings of the intuitive mode of human thinking.

12. In its present form, behavioral economics is not rooted in evolutionary theory, see Witt (2011) for a discussion.

13. Permanent structural change is endogenous to the modern 'capitalist engine' (Metcalfe 1998). It results from the ceaseless efforts of market participants to improve their competitive position. It is worth noting that such a view 
is difficult to align with the mechanical analogies introduced by the neoclassical writers. In a system of physical forces that is in an equilibrium state, change can only occur as a result of an impulse from outside the system. If what happens in a system of markets is modeled analogously to what happens in a system subject to physical forces, the consequence is that the causes of economic change have to be attributed to exogenous shocks.

14. Schumpeter (1955, Part IV, Chapter 3, Sec. 2b) devotes a whole subsection to discussing the tenets of Graebner, Koppers, and Ratzel.

15. In terms of the epistemological boundary separating the conditions of emergence of novelty from those of its diffusion, innovations as conceived by Schumpeter do not belong to the process of emergence (as inventions and discoveries do), but rather denote the beginning of a process of diffusion of novelty.

16. In the biological domain, the interpretative operation corresponds to the expression, and subsequent testing for viability and reproduction success, of a newly emerging genotype in its phenotypic counterpart.

17. The potential for law-like hypotheses which make negative predictions is not affected by the epistemological constraint. Such law-like hypotheses predict that a particular event is not expected whatever future novelty will hold, see Hayek (1964) for an example. Natural laws can always be used for deriving negative predictions.

18. The enormous impact of culturally accumulated, socially shared knowledge on modern economic behavior can be grasped by studying the 'economy' of primates. The stage of cultural development of many primate groups living today is most likely comparable to that of very early hominids. It is plausible therefore that the production and consumption activities of our early ancestors resembled what we observe in modern primates. By comparison with present-day forms of human production and consumption the long path of cultural evolution which the human species has undergone becomes readily apparent.

19. Theories of motivation 'describe why a person in a given situation selects one response over another or makes a given response with greater energization or frequency' (Bargh et al. 2010, p. 286).

20. For a time series displaying all the mentioned variations of household expenditure shares over a span of one hundred years see US Bureau of Labor Statistics, Report 991, 2006.

21. See, for instance, Streeten and Burki (1978), Thomson (1987), and Scanlon's (1975) distinction according to the suggested urgency of different preferences, or even much older Pigouvian notions of differences in urgency expressed in terms of a decreasing marginal utility of money.

22. The deeper problem implied here is thus the much discussed relationship between group selection and individual selection. See Sober and Wilson (1998), Field (2001), Henrich (2004), Wilson and Wilson (2007).

23. An explanatory strategy in which the policymaker is endogenized is, however, pursued in public choice theory, albeit narrowly confined to applications of the rational-actor model, see, for example, Mueller (1993).

\section{References}

Aghion, P. and P. Howitt (1992), 'A Model of Growth through Creative Destruction', Econometrica, 60, $323-51$.

Alchian, A.A. (1950), 'Uncertainty, Evolution, and Economic Theory', Journal of Political Economy, 58, 211-21.

Bargh, J.A., P.M. Gollwitzer and G. Oettingen (2010), 'Motivation', in S.T. Fiske, D.T. Gilbert and G. Lindzey (eds), Handbook of Social Psychology, New York: Wiley, 268-316.

Beck, N. (2015), 'The Garden of Orderly Polity: F.A. Hayek and T.H. Huxley's Views on Social Evolution', Journal of Bioeconomics, 17, 83-96.

Boehm, C. (2012), Moral Origins: The Evolution of Virtue, Altruism and Shame, New York: Basic Books.

Brown, G.R. and P.J. Richerson (2014), 'Applying Evolutionary Theory to Human Behavior: Past Differences and Current Debates', Journal of Bioeconomics, 16, 105-28.

Burnham, T., S.E.G. Lea, A. Bell, H. Gintis, P.W. Glimcher, R. Kurzban, L. Lades, K. McCabe, K. Panchanathan, M. Teschl and U. Witt (2015), 'Evolutionary Behavioral Economics', in D.S. Wilson and A. Kirman (eds), Complexity and Evolution - A New Synthesis for Economics, Cambridge, MA: MIT Press, in print.

Buss, D.M. (2003), Evolutionary Psychology: The New Science of the Mind, Boston: Allyn \& Bacon.

Campbell, D.T. (1965), 'Variation and Selective Retention in Socio-cultural Evolution', in H.R. Barringer, G.I. Blankstein and R.W. Mack (eds), Social Change in Developing Areas: A Re-interpretation of Evolutionary Theory, Cambridge, MA: Schenkman, 19-49.

Coase, R.H. (1960), 'The Problem of Social Cost', Journal of Law and Economics, 3, 1-44.

Cyert, R.M. and J.G. March (1963), A Behavioral Theory of the Firm, Englewood Cliffs, NJ: Prentice Hall.

Dawkins, R. (1983), 'Universal Darwinism', in D.S. Bendall (ed.), Evolution from Molecules to Man, Cambridge: Cambridge University Press, 403-25.

Dopfer, K., J. Foster and J. Potts (2004), 'Micro - Meso - Macro', Journal of Evolutionary Economics, 14, $263-79$.

Fagerberg, J. (2003), 'Schumpeter and the Revival of Evolutionary Economics: An Appraisal of the Literature', Journal of Evolutionary Economics, 13, 125-59.

Fauconnier, G. and M. Turner (2002), The Way We Think: Conceptual Blending and the Mind's Hidden Complexities, New York: Basic Books.

Field, A. (2001), Altruistically Inclined? The Behavioral Sciences, Evolutionary Theory, and the Origins of 
Reciprocity, Ann Arbor: University of Michigan Press.

Foster, J. (2011), 'Evolutionary Macroeconomics: A Research Agenda', Journal of Evolutionary Economics, 21, $5-28$.

Frank, R.H. (2010), Luxury Fever: Weighing the Cost of Excess, Princeton: Princeton University Press.

Frank, R.H. (2012), The Darwin Economy: Liberty, Competition, and the Common Good, Princeton: Princeton University Press.

Friedman, M. (1953), ‘The Methodology of Positive Economics', in M. Friedman (ed.), Essays in Positive Economics, Chicago: University of Chicago Press, 3-43.

Georgescu-Roegen, N. (1971), The Entropy Law and the Economic Process, Cambridge, MA: Harvard University Press.

Gigerenzer, G. and D.G. Goldstein (1996), 'Reasoning the Fast and Frugal Way: Models of Bounded Rationality', Psychological Review, 103, 650-69.

Glimcher, P. (2015), 'Proximate Mechanisms of Individual Decision-Making Behavior', in D.S. Wilson and A. Kirman (eds), Complexity and Evolution - A New Synthesis for Economics, Cambridge, MA: MIT Press, in print.

Gould, S.J. (1991), 'Exaptation: A Crucial Tool for an Evolutionary Psychology', Journal of Social Issues, 47, 43-65.

Gowdy, J. (1994), Coevolutionary Economics: The Economy, Society and the Environment, Boston: Kluwer Academic Publishers.

Gray, J. (1998), Hayek on Liberty, London: Routledge.

Hayek, F.A. (1941), The Pure Theory of Capital, London: Routledge and Kegan Paul.

Hayek, F.A. (1964), 'The Theory of Complex Phenomena', in M.A. Bunge (ed.), The Critical Approach to Science and Philosophy, New York: Free Press, 22-42.

Hayek, F.A. (1979), Law, Legislation, and Liberty, Vol. III: The Political Order of a Free People, London: Routledge and Kegan Paul.

Hayek, F.A. (1981), 'The Flow of Goods and Services', Notes of a Lecture given at L.S.E., January $27,1981$.

Hayek, F.A. (1988), The Fatal Conceit, London: Routledge.

Henrich, J. (2004), 'Cultural Group Selection, Coevolutionary Processes and Large-scale Cooperation', Journal of Economic Behavior and Organization, 53, 3-35.

Herrmann-Pillath, C. (2013), Foundations of Economic Evolution - A Treatise on the Natural Philosophy of Economics, Cheltenham, UK and Northampton, MA, USA: Edward Elgar Publishing.

Hodgson, G.M. (1995), 'The Evolution of Evolutionary Economics', Scottish Journal of Political Economy, 42, 469-88.

Hodgson, G.M. (2004), The Evolution of Institutional Economics, London: Routledge.

Hodgson, G.M. and K. Huang (2012), 'Evolutionary Game Theory and Evolutionary Economics: Are They Different Species?', Journal of Evolutionary Economics, 22, 345-66.

Hodgson, G.M. and T. Knudsen (2010), Darwin's Conjecture - The Search for General Principles of Social and Economic Evolution, Chicago: University of Chicago Press.

Hodgson, G.M., J. Järvinen and J.-A. Lamberg (2014), 'The Structure and Evolution of Evolutionary Research: A Bibliometric Analysis of the "Evolutionary" Literature in Management, Economics, and Sociology', Paper presented at the Annual Meetings of the European Association for Evolutionary Political Economy, Paris 2014.

Hull, D.L. (2001), Science and Selection: Essays on Biological Evolution and the Philosophy of Science, Cambridge: Cambridge University Press.

Jantsch, E. (1980), The Self-Organizing Universe, New York: Pergamon.

Kahneman, D. (2003), 'Maps of Bounded Rationality: Psychology for Behavioral Economics', American Economic Review, 93, 1449-75.

Kobayashi, D. (2014), 'Effects of Anthropology and Archaeology Upon Early Innovation Studies', Paper presented at the International Schumpeter Society Conference, Jena 2014.

Koppl, R., S. Kauffman, T. Felin and G. Longo (2015), 'Economics for a Creative World', Journal of Institutional Economics, 11, 1-31.

Leslie, J.C. (1996), Principles of Behavioral Analysis, Amsterdam: Harwood Academic Publishers.

Levit, G.S., U. Hossfeld and U. Witt (2011), 'Can Darwinism Be “Generalized” and of What Use Would This Be?', Journal of Evolutionary Economics, 21, 545-62.

Loewenstein, G. (2000), 'Emotions in Economic Theory and Economic Behavior', American Economic Review, 90, 426-32.

Loewenstein, G. (2004), 'Out of Control: Visceral Influences on Behavior', in C.F. Camerer, G. Loewenstein and M. Rabin (eds), Advances in Behavioral Economics, Princeton: Princeton University Press, 689-723.

March, J.G. and H.A. Simon (1958), Organizations, New York: Wiley.

Mas-Colell, A., M.D. Whinston and J.R. Green (1995), Microeconomic Theory, Oxford: Oxford University Press.

McCormick, B.J. (1992), Hayek and the Keynesian Avalanche, New York: Harvester Wheatsheaf.

Metcalfe, J.S. (1994), 'Evolutionary Economics and Technology Policy’, Economic Journal, 104, 931-44. 
Metcalfe, J.S. (1998), Evolutionary Economics and Creative Destruction, London: Routledge.

Metcalfe, J.S. (2002), 'On the Optimality of the Competitive Process: Kimura's Theorem and Market Dynamics', Journal of Bioeconomics, 4, 109-33.

Metcalfe, J.S. (2008), 'Accounting for Economic Evolution: Fitness and the Population Method', Journal of Bioeconomics, 10, 23-50.

Mirowski, P. (1989), More Heat Than Light - Economics as Social Physics, Physics as Nature's Economics, Cambridge: Cambridge University Press.

Mueller, D.C. (1993), The Public Choice Approach to Politics, Aldershot, UK and Brookfield, VT, USA: Edward Elgar Publishing.

Nelson, R.R. (2006), 'Evolutionary Social Science and Universal Darwinism', Journal of Evolutionary Economics, 16, 491-510.

Nelson, R.R. and S.G. Winter (1982), An Evolutionary Theory of Economic Change, Cambridge, MA: Harvard University Press.

Nelson, R.R. and S.G. Winter (2002), 'Evolutionary Theorizing in Economics', Journal of Economic Perspectives, 16, 23-46.

North, D.C. (1997), Institutions, Institutional Change and Economic Performance, Cambridge: Cambridge University Press.

Penrose, E.T. (1952), 'Biological Analogies in the Theory of the Firm', American Economic Review, 42, 804-19.

Popper, K.R. (1960), The Poverty of Historicism, London: Routledge and Kegan Paul.

Reinganum, J.F. (1985), 'Innovation and Industry Evolution', Quarterly Journal of Economics, 100, 81-99.

Rice, C. and J. Smart (2011), 'Interdisciplinary Modeling: A Case Study of Evolutionary Economics', Biology \& Philosophy, 26, 655-75.

Richerson, P.J. and R. Boyd (2005), Not by the Genes Alone: How Culture Transformed Human Evolution, Chicago: University of Chicago Press.

Samuelson, L. (2002), 'Evolution and Game Theory', Journal of Economic Perspectives, 16, 47-66.

Scanlon, T. (1975), 'Preference and Urgency', Journal of Philosophy, 72, 655-69.

Schumpeter, J.A. (1934[1912]), Theory of Economic Development, Cambridge, MA: Harvard University Press (first published as Theorie der Wirtschaftlichen Entwicklung, 1912).

Schumpeter, J.A. (1942), Capitalism, Socialism and Democracy, New York: Harper.

Schumpeter, J.A. (1955), History of Economics Analysis, London: Allen \& Unwin.

Schumpeter, J.A. (2002), 'The Economy as a Whole' (Seventh Chapter of Theorie der Wirtschaftlichen Entwicklung, 1912, English translation by U. Backhaus), Industry and Innovation, 9, 93-145.

Scitovsky, T. (1962), 'On the Principle of Consumers' Sovereignty', American Economic Review, 52, $262-8$.

Scitovsky, T. (1981), 'The Desire for Excitement', Kyklos, 34, 3-13.

Silva, S.T. and A.C. Teixeira (2009), 'On the Divergence of Evolutionary Research Paths in the Past 50 Years: A Comprehensive Bibliometric Account', Journal of Evolutionary Economics, 19, 605-42.

Simon, H.A. (1955), 'A Behavioral Model of Rational Choice', Quarterly Journal of Economics, 69, 99-118.

Smith, A. (1976[1776]), An Inquiry into the Nature and Causes of the Wealth of Nations, Oxford: Oxford University Press.

Sober, E. and D.S. Wilson (1998), Unto Others - The Evolution and Psychology of Unselfish Behavior, Cambridge MA: Harvard University Press.

Streeten, P. and S. Burki (1978), 'Basic Needs: Some Issues’, World Development, 6, 411-21.

Streissler, E. (1982), 'Schumpeter's Vienna and the Role of Credit in Innovation', in H. Frisch (ed.), Schumpeterian Economics, New York: Praeger, 60-83.

Thomson, G. (1987), Needs, London: Routledge and Kegan Paul.

Tinbergen, J. (1967), Economic Policy: Principles and Design, Amsterdam: North-Holland.

van den Bergh, J.C.J.M. (2007), 'Evolutionary Thinking in Environmental Economics', Journal of Evolutionary Economics, 17, 521-49.

van den Bergh, J.C.J.M and G. Kallis (2013), 'A Survey of Evolutionary Policy: Normative and Positive Dimensions', Journal of Bioeconomics, 15, 281-303.

Veblen, T. (1898), 'Why Is Economics Not an Evolutionary Science?', Quarterly Journal of Economics, 12, $373-97$.

Veblen, T.B. (1899), The Theory of the Leisure Class - An Economic Study of Institutions, New York: MacMillan.

Veblen, T.B. (1914), The Instinct of Workmanship, and the State of the Industrial Arts, New York: MacMillan.

Weibull, J.W. (1995), Evolutionary Game Theory, Cambridge, MA: MIT Press.

Wilson, D.S. (2015), 'Two Meanings of Complex Adaptive Systems', in D.S. Wilson and A. Kirman (eds), Complexity and Evolution - A New Synthesis for Economics, Cambridge, MA: MIT Press, in print.

Wilson, D.S. and E.O. Wilson (2007), 'Rethinking the Theoretical Foundation of Sociobiology', The Quarterly Review of Biology, 82, 327-48.

Winter, S.G. (1964), 'Economic "Natural Selection" and the Theory of the Firm', Yale Economic Essays, 4, $225-72$.

Winter, S.G. (2014), 'The Future of Evolutionary Economics: From Early Intuitions to a New Paradigm?', Journal of 


\section{xxxiv Rethinking Economic Evolution}

Institutional Economics, 10, 613-44.

Witt, U. (1985), 'Coordination of Individual Economic Activities as an Evolving Process of Self-Organization', Économie Appliquée, 38, 569-95.

Witt, U. (2001), 'Learning to Consume - A Theory of Wants and the Growth of Demand', Journal of Evolutionary Economics, 11, 23-36.

Witt, U. (2010), 'Symbolic Consumption and the Social Construction of Product Characteristics', Structural Change and Economic Dynamics, 21, 17-25.

Witt, U. (2011), 'Economic Behavior - Evolutionary Versus Behavioral Perspectives', Biological Theory, 6, 388-98. Witt, U. (2015), 'Causality and Regularity in a "Creative World"', Journal of Institutional Economics, 11, 55-60. 